\title{
Antiproliferative effect of double suicide gene delivery mediated by polyamidoamine dendrimers in human Tenon's capsule fibroblasts
}

\author{
JIN YANG ${ }^{1}$, LIU KUN SHI ${ }^{2}$, HUI MIN SUN ${ }^{3}$ and YAN MING WANG ${ }^{4}$ \\ ${ }^{1}$ Tianjin Eye Hospital, Tianjin Key Laboratory of Ophthalmology and Vision Science, Clinical College \\ of Ophthalmology, Tianjin Medical University, Tianjin 300020; ${ }^{2}$ Department of Ophthalmology, Tianjin \\ Medical University; ${ }^{3}$ Department of Glaucoma, College of Optometry and Ophthalmology, Tianjin \\ Medical University Eye Institute, Tianjin Medical University Eye Hospital, Tianjin Medical University, \\ Tianjin 300384; ${ }^{4}$ College of Pharmacy, Nankai University, Tianjin 300071, P.R. China
}

Received December 29, 2016; Accepted July 27, 2017

DOI: $10.3892 / \mathrm{etm} .2017 .5235$

\begin{abstract}
The aim of the present study was to investigate the therapeutic potential of a double suicide gene, thymidine kinase (TK) combined with cytosine deaminase (CD), mediated by generation of 5-polyamidoamine dendrimers (G5-PAMAM-D) on human Tenon's capsule fibroblasts (HTFs) as an anti-scarring agent. The pAcGFP1-Hyg-TK-CD plasmid was transfected into HTFs, and reverse-transcription polymerase chain reaction (RT-PCR) was used to detect TK-CD expression. MTT cell proliferation assay was used to evaluate the cytotoxic effects of ganciclovir (GCV) and 5-flurocytosine (5-FC) on HTFs. The optimal concentration of GCV and 5-FC in TK-CD transfected HTFs (HTF-TK-CD) was selected by accessing the lowest and highest cytotoxicity caused, respectively. The morphological changes of transfected HTFs following treatment with GCV and 5-FC were observed by light and transmission electron microscopy. Results demonstrated that the double suicide gene TK-CD mediated by the G5-PAMAM-D delivery system was successfully expressed in HTFs as determined by RT-PCR. A concentration of $3 \mu \mathrm{g} / \mathrm{ml}$ $\mathrm{GCV}$ and $200 \mu \mathrm{g} / \mathrm{ml} 5$-FC was identified as optimal for these prodrugs. The growth rate and number of HTF-TK-CD cells decreased following treatment with GCV and 5-FC as revealed by light microscopy. Additionally, the prodrugs GCV and 5-FC not only demonstrated toxicity on transfected HTFs but also exerted a 'bystander effect'. The present study illustrated that the double suicide gene TK-CD delivery mediated by
\end{abstract}

Correspondence to: Dr Jin Yang, Tianjin Eye Hospital, Tianjin Key Laboratory of Ophthalmology and Vision Science, Clinical College of Ophthalmology, Tianjin Medical University, 4 Gansu Road, Tianjin 300020, P.R. China

E-mail: yangjin979@163.com

Key words: glaucoma, polyamidoamine dendrimer, suicide gene, human Tenon's capsule fibroblast, gene transfer
G5-PAMAM-D was effective in reducing HTF proliferation and inducing cell apoptosis. Furthermore, TK-CD delivery mediated by G5-PAMAM-D may be used as an anti-scarring agent and provide a therapeutic potential for patients requiring glaucoma filtration surgery.

\section{Introduction}

Glaucoma filtration surgery has been established as an effective therapeutic method for intraocular pressure control (1). However, excess proliferation of fibroblasts in the filtration area following surgery leads to scarring and is the predominant cause of surgery failure (2-4). To suppress the overreactive wound healing process and reduce bleb scarring in high risk cases, antimetabolic agents, including mitomycin-c and 5-fluorouracil (5-FU), may be used during surgery (5). Clinically, the use of antimetabolites may ameliorate postoperative effects in numerous cases that demonstrate a high risk of failure $(1,5)$. These agents are thought to improve the success rate of surgery; however, they are also associated with notable complications, including hypotony, bleb leaks, blebitis and endophthalmitis (5).

It has been reported that transfer of the herpes virus thymidine kinase (TK) gene into tumor cells could lead to cell death following administration of a prodrug (6). The Eschericha coli gene coding for the cytosine deaminase (CD) enzyme was identified to serve as another suicide gene (7). These two gene-directed enzyme prodrug therapies have been investigated extensively, including studies in clinical trials (8). The double suicide gene system, TK- $\mathrm{CD}$, exhibited a stronger effect on cell death compared to the TK or CD genes alone $(7,9)$.

Viral vectors have been mostly used for suicide gene therapy; however, certain limitations remain. For example, retroviruses only transduce a dividing cell, lentiviruses may induce oncogenesis and herpes simplex virus (HSV) may cause inflammation (9-11). Nanoparticles exhibited unique properties that may provide a platform to overcome the limitations of viral vectors (12). The spherical-like nanoparticles may be used to carry DNA for protecting their cargo from degradation 
and regulating their release (12). Furthermore, the use of nanotechnology in drug delivery has been growing rapidly recently (13). Advances in molecular biology and genetic engineering have allowed suicide gene therapy to represent a potential approach for regulating scarring following glaucoma filtration surgery (8). The present study investigated the antiproliferative effect of a double suicide gene, TK combined with $\mathrm{CD}$, using non-viral vector generation 5-polyamidoamine dendrimers (G5-PAMAM-D) on human Tenon's capsule fibroblasts (HTFs) in vitro.

\section{Materials and methods}

Cells, reagents and instruments. HTFs were obtained from Tenon's capsule tissues of 5 patients (age range, 36-61 years; mean age, $47.4 \pm 12.3$ years; 4 males and 1 female, sample collection between October 2015 and January 2016) undergoing surgery to treat glaucoma at Tianjin Eye Hospital (Tianjin, China). Tissues were prepared for culture in $35 \mathrm{~mm}$ Petri tissue-culture dishes that contained Dulbecco's modified Eagle's medium (DMEM; Tianjin Haoyang Biotechnology Co., Ltd., Tianjin, China), supplemented with $10 \%$ fetal bovine serum (Tianjin Haoyang Biotechnology Co., Ltd.) Cells were incubated at $37^{\circ} \mathrm{C}$ in a humidified environment of $95 \%$ air and $5 \% \mathrm{CO}_{2}$. Following tissue culture, third to sixth generation cells were prepared for experiments. The present study was approved by the Institutional Review Board of Tianjin Eye Hospital (Tianjin, China) and the Human Research Ethics Committee of Tianjin Eye Hospital (Tianjin, China). Patient informed consent was obtained prior to initiation of the study.

The restriction enzymes EcoRI, XhoI, HindIII and KpnI, and DNA ladder marker (1 kbp) were purchased from Takara Bio, Inc., (Otsu, Japan). T4 DNA ligase, Probest DNA polymerase and protein marker $(2-212 \mathrm{kDa})$ were purchased from New England Biolabs, Inc., (Ipswich, MA, USA). An agarose gel DNA extraction kit was purchased from Tiangen Biotech Co., Ltd., (Beijing, China). Ganciclovir (GCV) was purchased from Shanghai New Pioneer Pharmaceutical Co., Ltd., (Shanghai, China) and 5-flurocytosine (5-FC) was purchased from Shanghai Shunqiang Biotechnology Co., Ltd., (Shanghai, China). MTT and dimethyl sulfoxide (DMSO) were purchased from Sigma-Aldrich (Merck KGaA, Darmstadt, Germany).

The instruments that were used in the present study were as follows: GeneAmp9600PCR (PerkinElmer, Inc., Waltham, MA, USA), OLYMPUS Ix53 optical microscope (Olympus Corporation, Tokyo, Japan), an OLYMPUS IX71 inverted fluorescence microscope and camera system (Olympus Corporation), BD FACS Calibur Flow Cytometer (BD Biosciences, San Jose, CA, USA) and Philips EM400ST transmission electron microscope (Philips Healthcare, Amsterdam, The Netherlands).

Vector and plasmid construction. G5-PAMAM-D, plasmid pAcGFP1-Hyg-CD and E. coli DH5 $\alpha$ were kindly provided by the Pharmacy College of Nankai University (Tianjin, China). The HSV/TK gene plasmid, pMD18-TK, was obtained from Takara Bio, Inc. The CD expression plasmid, pAcGFP1-Hyg-CD, was obtained by polymerase chain reaction (PCR) and restriction enzyme digestion from the $\mathrm{CD}$ gene.
The TK gene fragment was amplified from the plasmid pMD18-TK by PCR with Probest DNA polymerase (New England Biolabs, Inc.). The thermocycling conditions for the reaction were as follows: $94^{\circ} \mathrm{C}$ for $5 \mathrm{~min}$, followed by 35 cycles of $94^{\circ} \mathrm{C}$ for $30 \mathrm{sec}, 52^{\circ} \mathrm{C}$ for $30 \mathrm{sec}, 72^{\circ} \mathrm{C}$ for $90 \mathrm{sec}$; followed by $72^{\circ} \mathrm{C}$ for $10 \mathrm{~min}$. The following primers were used: TK-S1, forward primer, 5'-GCTAAGCTTATGGCCTCG TACCCCGGCCA-3' (italicized part indicates the cutting site of HindIII) and TK-A1, reverse primer, 5'-CGCGGATCC TCAGTTAGCCTCCCCCAT-3' (italicized part indicates the cutting site of BamHI). The amplified TK gene PCR fragment $(1,143 \mathrm{bp})$ and the expression vector pAcGFP1-HygN1 (5.8 kb; Clontech Laboratories, Inc., Mountainview, CA, USA) were digested with BamHI and HindIII and then ligated to obtain the pAcGFP1-Hyg-TK product $\left(37^{\circ} \mathrm{C}\right.$ for $\left.4 \mathrm{~h}\right)$.

The TK gene fragment was further amplified by PCR with Probest DNA polymerase. The thermocycling conditions for the reaction were as described above. The following primers were used: TK-S2, forward primer, 5'-CCGCTCGAG ATGGCCTCGTACCCCGGCCATCAACA-3' (italicized part indicates the cutting site of XhoI) and TK-A2, reverse primer, 5'-CGAAAGCTTACCAGAACCACCGTTAGCCTC CCCCATCTCCCGGGCA-3' (italicized part indicates the cutting site of HindIII). The TK gene PCR fragment (1,143 bp) and expression vector, pAcGFP1-Hyg-CD (6,262 bp), were digested by XhoI and HindIII and then ligated to obtain the final plasmid, pAcGFP1-Hyg-TK-CD. Finally, the plasmid sequence was verified by DNA sequencing, and the plasmid was further amplified and purified by a QIAfilter ${ }^{\mathrm{TM}}$ plasmid maxi kit (Qiagen China Co., Ltd., Shanghai, China), according to the manufacturer's protocol.

HTF plasmid transfection. A total of $2.0 \mu \mathrm{g} / \mathrm{ml}$ pAcGFP1-Hyg-TK-CD plasmid and PAMAM-D were mixed (mass ratio, 1:2) and incubated for $30 \mathrm{~min}$ at $25^{\circ} \mathrm{C}$. Logarithmic growth phase HTFs were trypsinized and plated in 24-well plates $\left(5 \times 10^{4} /\right.$ well). After $24 \mathrm{~h}$ when the cell confluency reached $70-75 \%$, cells were divided into experimental (G5-PAMAM-D/TK-CD), positive control (Lipofectamine 2000 transfection and Lipo/TK-CD) and negative control (pAcGFP1-Hyg-TK-CD plasmid alone) groups, and each assay was repeated in triplicate. Lipofectamine ${ }^{\circledR} 2000$ was purchased from Invitrogen (Thermo Fisher Scientific, Inc.).

TK and CD gene expression analysis. After $48 \mathrm{~h}$ of transfection, transfection efficiency was assessed by observation of green fluorescent protein expression. Total cell RNA was extracted from transfected HTFs $48 \mathrm{~h}$ after transfection with TRIzol reagent (Invitrogen; Thermo Fisher Scientific, Inc.) and then one-step reverse transcription (RT)-PCR was performed using a Transcriptor One-step RT-PCR kit (Roche Diagnostics, Basel, Switzerland), according to the manufacturer's protocol. The thermocycling conditions for the RT reaction were as follows: $42^{\circ} \mathrm{C}$ for $2 \mathrm{~h}, 95^{\circ} \mathrm{C}$ for $5 \mathrm{~min}$, preserved at $20^{\circ} \mathrm{C}$. PCR reaction conditions were as follows: $95^{\circ} \mathrm{C}$ for $5 \mathrm{~min}$, followed by 32 cycles of $94^{\circ} \mathrm{C}$ for $50 \mathrm{sec}, 52^{\circ} \mathrm{C}$ for $50 \mathrm{sec}, 72^{\circ} \mathrm{C}$ for $1 \mathrm{~min}$, then $72^{\circ} \mathrm{C}$ for $8 \mathrm{~min}$. The following primers were used: Forward, $5^{\prime}-\mathrm{GGG}$ TCTAGAATGGCTTCGTACCCC-3' and reverse, 5'-TCTGTT AACTCAGTTAGCCTCCCCCATCTCCCG-3'. The TK-CD PCR product was analyzed by $1 \%$ agarose gel electrophoresis 
and an Image Master Total Lab gel imaging analytical system version 2.0 (TotalLab Ltd., Newcastle upon Tyne, UK) was used to analyze nucleic acid bands.

Cell viability assay. MTT colorimetric assay was used to evaluate the lethal effect and optimal concentration of a prodrug on HTF and HTF-TK-CD cells. Cells were plated in 96-well plates (cell concentration $1 \times 10^{4}$ cells $/ \mathrm{ml}$ ) in $200 \mu \mathrm{l}$ DMEM. After $24 \mathrm{~h}$ of culture, HTF-TK-CD and HTF cells were observed to exhibit robust growth under a light microscope. The concentration of GCV was tested at $0,1,2,3,4,5$, 8 or $10 \mu \mathrm{g} / \mathrm{ml}$, and the concentration of $5-\mathrm{FC}$ was tested at 0 , $50,100,200,400,600,800$ or $1,000 \mu \mathrm{g} / \mathrm{ml}$. The blank control, experimental and control groups were set up in four replicate groups. In total, $72 \mathrm{~h}$ after $\mathrm{GCV}$ and $5-\mathrm{FC}$ treatment at $37^{\circ} \mathrm{C}$, the cell viability was determined using the MTT assay. A total of $20 \mu \mathrm{l}$ MTT solution $(5 \mathrm{mg} / \mathrm{ml})$ was added to each well and incubated for $4 \mathrm{~h}$ at $37^{\circ} \mathrm{C}$. The culture medium was then removed, followed by the addition of $150 \mu \mathrm{l}$ DMSO to each well and incubation for an additional $10 \mathrm{~min}$. Subsequently, the absorbance (optical density; OD) of each well was measured using an enzyme immunoassay analyzer at a wavelength of $490 \mathrm{~nm}$. The cell survival rate (\%) was calculated according to the following formula: (Experimental group OD value/blank control group OD value) x100.

To evaluate the bystander effect of the TK-CD gene, untransfected cells were mixed in an increased proportion of HTF-TK-CD cells at $10,20,30,40,50,60,70,80,90$ or $100 \%$. The cells were then plated into 96 -well plates at $1 \times 10^{4}$ cells/well in four replicate groups.

To each well, $3 \mu \mathrm{g} / \mathrm{ml} \mathrm{GCV}$ and/or $200 \mu \mathrm{g} / \mathrm{ml} 5$-FC were added in DMEM. After $72 \mathrm{~h}$ at $37^{\circ} \mathrm{C}$, the cell inhibition ratio was determined using the MTT colorimetric assay, where the cell inhibition rate $(\%)$ was calculated according to the following formula: (1-experimental group OD value/blank control group OD value) x100.

Light and transmission electron microscopy. A total of $1 \times 10^{5}$ HTFs cells or HTF-TK-CD cells were divided into groups A, $\mathrm{B}, \mathrm{C}$ and D and plated into 6-well culture plates. GCV and/or 5-FC in DMEM media was added as follows: Group A, GCV $3 \mu \mathrm{g} / \mathrm{ml}$; group B, 5-FC $200 \mu \mathrm{g} / \mathrm{ml}$; group C, GCV $3 \mu \mathrm{g} / \mathrm{ml}$ and 5-FC $200 \mu \mathrm{g} / \mathrm{ml}$; and group D, DMEM without prodrug. Each condition was prepared in duplicate. Furthermore, the morphological changes of the cells were observed using an inverted microscope after $24 \mathrm{~h}\left(37^{\circ} \mathrm{C}\right)$ of prodrug treatment.

For transmission electron microscopy, after $72 \mathrm{~h}\left(37^{\circ} \mathrm{C}\right)$ of cell culture, cells were washed with PBS three times, trypsinized and collected. Cells were then centrifuged at $251.5 \mathrm{x} \mathrm{g}$ (room temperature) for $2 \mathrm{~min}$, washed with $4^{\circ} \mathrm{C}$ precooled PBS twice, fixed in $4^{\circ} \mathrm{C}$ precooled $3 \%$ glutaraldehyde for $4 \mathrm{~h}$ and rinsed with PBS for 10 min three times. Subsequently, cells were fixed with $1 \%$ osmium tetroxide for $2 \mathrm{~h}$ at room temperature, rinsed with PBS for 10 min three times, dehydrated with $30-100 \%$ alcohol and embedded (at $37^{\circ} \mathrm{C}$ ) with SPI-PON 812 resin. Following this, the samples were cut into slices $(100 \mathrm{~nm}$ thick) with a LKBV-type ultramicrotome, double-stained with $3 \%$ uranyl acetate for $3 \mathrm{~min}$ and $2 \%$ lead citrate for $20 \mathrm{~min}$ at room temperature and observed under a transmission electron microscope (magnification, $\mathrm{x} 3,400$ or $\mathrm{x} 5,700$ ).
Statistical analysis. Statistical analysis was performed using SPSS version 19.0 (IBM Corp., Armonk, NY, USA). Data were presented as the mean \pm standard deviation. The effects of different concentrations of GCV and 5-FC on the two groups were analyzed using linear regression analysis. Differences between the combined and individual treatment groups in cell survival were compared using two-way analysis of variance (ANOVA) for each concentration. The Student-Newman-Keuls (SNK) method was used for pair-wise comparisons and comparisons among various groups were performed using Dunnett's test. $\mathrm{P}<0.05$ was considered to indicate a statistically significant difference.

\section{Results}

TK-CD plasmid verification and expression in HTF cells. To verify the constructed plasmid (pAcGFP1-Hyg-TK-CD), the plasmid was digested with XhoI and KpnI and the 1,617 bp fragment of the TK-CD gene was confirmed by DNA gel electrophoresis on a $1 \%$ agarose gel (Fig. 1A and B). RT-PCR analysis indicated that the expected band (403 bp) was observed in HTF cells transfected with the pAcGFP1-Hyg-TK-CD plasmid, while $\beta$-actin (561 bp) was present in the transfected and non-transfected groups (Fig. 1C). TK and CD gene expression mediated by either Lipofectamine ${ }^{\circledR} 2000$ or G5-PAMAM-D was further accessed by fluorescence microscopy. As indicated in Fig. 1D, TK-CD-green fluorescent protein expression was observed in Lipofectamine ${ }^{\circledR} 2000$-transfected and G5-PAMAM-D-mediated HTF cells.

Dose optimization of prodrug on HTF and HTF-TK-CD cells. The MTT assay in HTF cells indicated that the cell survival rate significantly decreased as the concentration of GCV and/or 5-FC added increased (all $\mathrm{P}<0.05$; Fig. 2). A significant linear correlation $\left(\mathrm{Y}_{\mathrm{GCV}}=103.81-5.67 \mathrm{X}, \mathrm{P}<0.05 ; \mathrm{Y}_{5-\mathrm{FC}}=97.06-0.06 \mathrm{X}\right.$, $\left.\mathrm{P}<0.05 ; \mathrm{Y}_{\mathrm{GCV}+5-\mathrm{FC}}=112.68-9.18 \mathrm{X}, \mathrm{P}<0.05\right)$ was detected by simple linear regression analysis. Similarly, the survival rate of HTF-TK-CD cells significantly decreased as the concentration of GCV and/or 5-FC added increased (all $\mathrm{P}<0.05$ ); however, no linear correlation was detected. ANOVA analysis (with SNK method) indicated that the F values for 5-FC, GCV and GCV+5-FC were 3,150.07, 3,125.22 and 3,114.35, respectively. The cell survival rate was significantly decreased $(\mathrm{P}<0.05)$ when the 5 -FC concentration was $<400 \mu \mathrm{g} / \mathrm{ml}$. When the concentration for the 5-FC group was 100,200 or $1,000 \mu \mathrm{g} / \mathrm{ml}$, the HTF cell survival rate was $88.07,81.66$ or $40.03 \%$, respectively. In the HTF-TK-CD group, $100 \mu \mathrm{g} / \mathrm{ml}$ of 5-FC appeared to be toxic to the cells as its cell survival rate decreased to $45.38 \%$ when compared to $88.07 \%$ of the cell survival rate in the HTF group. Similarly, a cell survival rate of $38.46 \%$ at $200 \mu \mathrm{g} / \mathrm{ml}$ of 5 -FC in the HTF-TK-CD group was comparable to a cell survival rate of $40.03 \%$ at $1,000 \mu \mathrm{g} / \mathrm{ml}$ of 5 -FC in the HTF group. When the 5-FC concentration was $>200 \mu \mathrm{g} / \mathrm{ml}$ in the HTF-TK-CD group $(400,600,800$ and $1000 \mu \mathrm{g} / \mathrm{ml})$, the cell survival rate was decreased, but it was not significantly different (all $\mathrm{P}>0.05$ ). By contrast, when the 5-FC concentration was $\leq 200 \mu \mathrm{g} / \mathrm{ml}$, the cell survival rate was significantly different (all $\mathrm{P}<0.05)$.

Therefore, $200 \mu \mathrm{g} / \mathrm{ml}$ of 5-FC was selected for subsequent experiments as this concentration could prevent 5-FC-mediated 
A

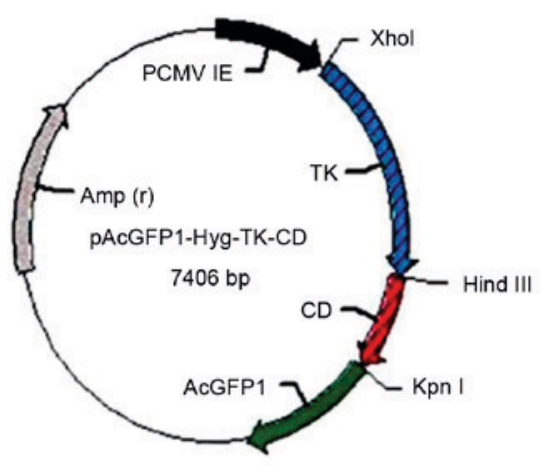

C

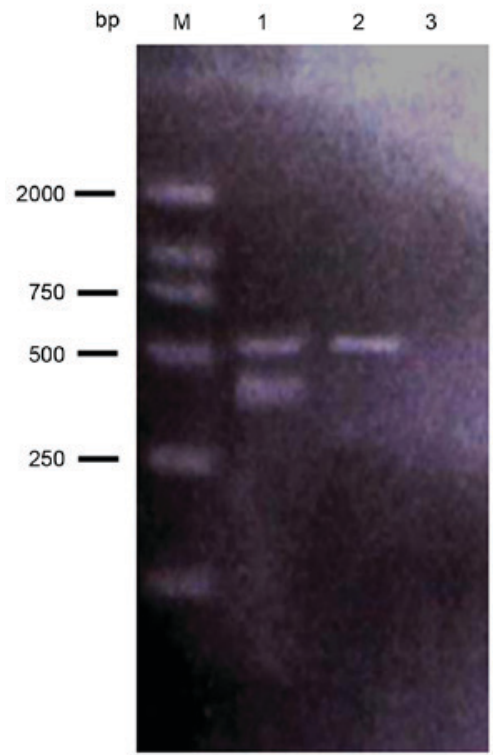

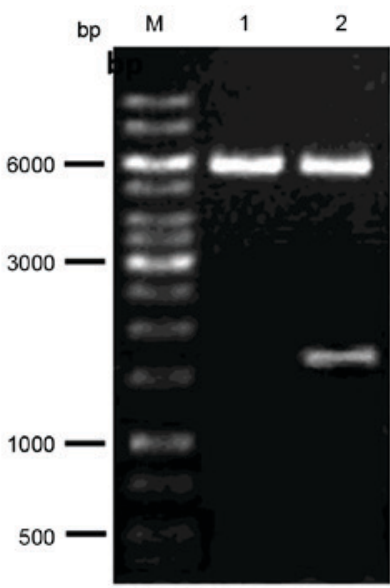

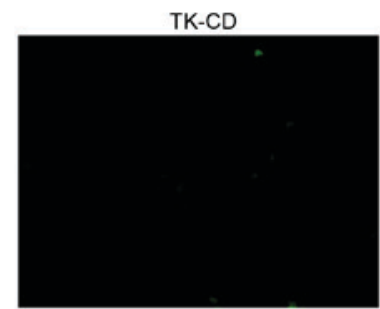

Lipo/TK-CD (ctrl)

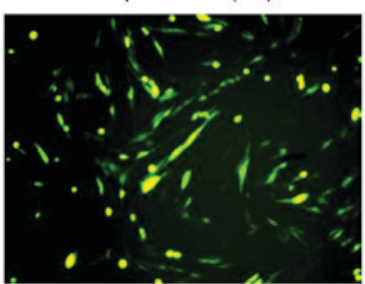

G5-PAMAM-D/TK-CD

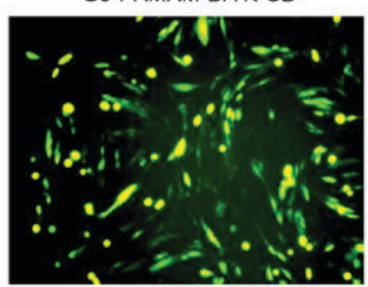

Figure 1. TK and CD gene expression in HTF cells. (A) The plasmid map showing the expression vector, pAcGFP1-Hyg, carrying the TK and CD genes. (B) The $1,617 \mathrm{bp}$ fragment of the TK-CD gene was confirmed by restriction enzyme digestion of the plasmid with XhoI and KpnI followed by $1 \%$ DNA gel electrophoresis. Lane M, DNA marker; lane 1, vector pAcGFP1-Hyg; and lane 2, pAcGFP1-Hyg-TK-CD. (C) Reverse transcription-polymerase chain reaction analysis of HFT cells transfected with pAcGFP1-Hyg-TK-CD. Lane M, DL2000 marker; lane 1, fragment of TK-CD (403 bp) and $\beta$-actin (561 bp) in the transfected cells; lane 2, untransfected; and lane 3, negative control groups. (D) TK and CD gene expression mediated either by Lipo or G5-PAMAM-D was accessed by fluorescence microscopy (magnification, x100). TK, thymidine kinase; CD, cytosine deaminase; HTFs, human Tenon's capsule fibroblasts; G5-PAMAM-D, 5-polyamidoamine dendrimers; bp, base pairs; Lipo, Lipofectamine 2000; ctrl, control.

cytotoxicity and effectively exert an inhibitory effect on the suicide gene. Similarly, $3 \mu \mathrm{g} / \mathrm{ml}$ of $\mathrm{GCV}$ was also selected based on the same criteria. In total, $200 \mu \mathrm{g} / \mathrm{ml} 5$-FC and/or $3 \mu \mathrm{g} / \mathrm{ml} \mathrm{GCV}$ represented an optimal concentration and were used in the present study.

Bystander effect of the TK-CD double suicide gene. The bystander effect of the TK-CD suicide gene was further evaluated. As indicated in Fig. 3, $3 \mu \mathrm{g} / \mathrm{ml} \mathrm{GCV}$ and/or $200 \mu \mathrm{g} / \mathrm{ml}$ 5-FC demonstrated an increased inhibition of cell proliferation when HTF cells were mixed with an increased number of
HTF-TK-CD cells. When the ratio of transfected cells was $40 \%$ (HTF-TK-CD: HTF ratio=4:6), the combined treatment with $5-\mathrm{FC} / \mathrm{GCV}$ revealed a significant inhibition of $48.6 \pm 1.28 \%$ compared to the control $(\mathrm{P}<0.05)$; however, a significant difference was not observed with 5-FC (38.2 $\pm 0.47 \%)$ or GCV $(24.6 \pm 0.86 \%)$ treatment alone. Similarly, when the ratio of transfected cells was $>70 \%$, all three groups of $5 \mathrm{FC} / \mathrm{GCV}$ combined group, 5FC group and GCV group revealed significantly different cell proliferation inhibition rates, and the 5-FC/GCV combination group appeared to be the most significantly different among the three groups $\left(\mathrm{T}_{\text {combined with } 5-\mathrm{FC}}=6.37\right.$, 

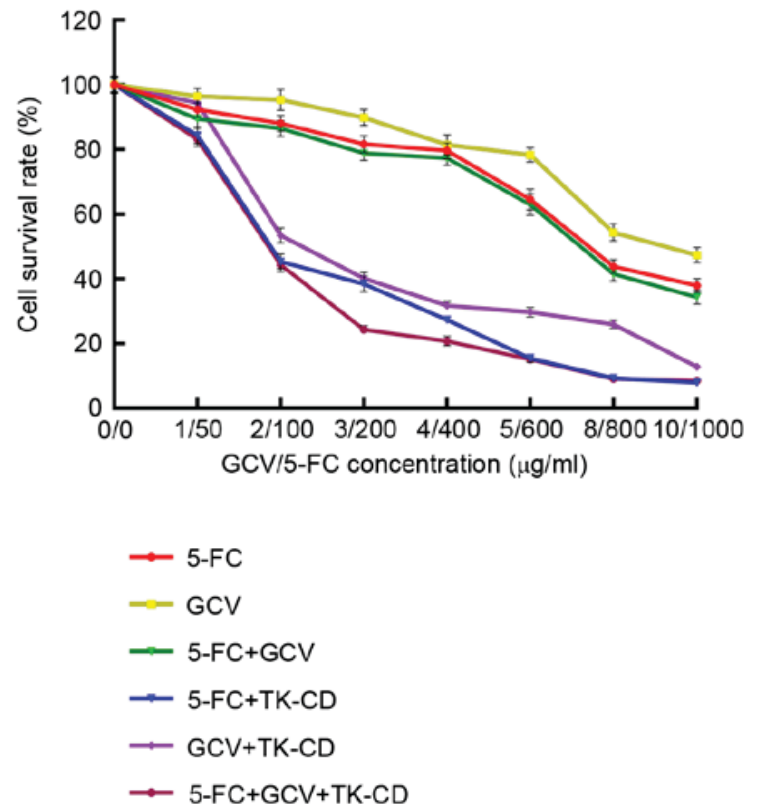

Figure 2. Effect of 5-FC and GCV on cell survival rate (\%) of HTF and HTF-TK-CD cells was evaluated by adjusting the concentration of prodrugs in the MTT assay. 5-FC, 5-flurocytosine; GCV, ganciclovir; HTFs, human Tenon's capsule fibroblasts; TK, thymidine kinase; $\mathrm{CD}$, cytosine deaminase.

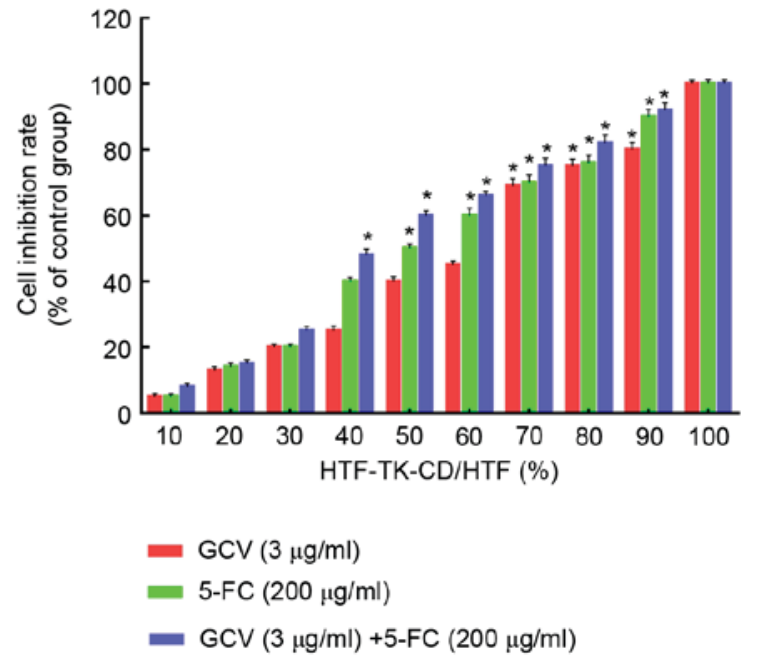

Figure 3. Effect of 5-FC and GCV on the inhibition of cell proliferation in HTF cells mixed with an increased number of HTF-TK-CD cells. Proliferation was expressed as a percentage of the inhibition for HTFs transfected with the TK-CD gene (control group, set as $100 \%$ ) ${ }^{*} \mathrm{P}<0.05$ vs. control group, by Dunnett's test $(\mathrm{n}=4)$. 5-FC, 5 -flurocytosine; GCV, ganciclovir; HTFs, human Tenon's capsule fibroblasts; TK, thymidine kinase; $\mathrm{CD}$, cytosine deaminase.

$\left.\mathrm{T}_{\text {combined with GCV }}=11.32 ; \mathrm{P}<0.05\right)$. These data indicated that the bystander effect of $5 \mathrm{FC} / \mathrm{GCV}$ combined group was greater than 5-FC or GCV treatment alone.

Light and transmission electron microscopy. The effect of 5-FC and GCV on HTF cell morphology was accessed by light microscopy. The morphology of HTF cells following treatment with $3 \mu \mathrm{g} / \mathrm{ml} \mathrm{GCV}$ and/or $200 \mu \mathrm{g} / \mathrm{ml} 5$-FC was comparable to non-treated HTF cells (Fig. 4A and B). HTF cells were relatively transparent, adherent and healthy following treatment with GCV and/or 5-FC. The number of cells and cellular proliferation demonstrated no clear difference amongst the three groups (GCV, 5-FC or GCV/5-FC). Furthermore, changes of morphology were observed in HTF-TK-CD cells following treatment with GCV and/or 5-FC as compared with the control group (Fig. 4C). Additionally, the quantity of intracellular granules increased, cells shrunk, exhibited lower adherence and appeared less healthy. The number of cells was also reduced among the three groups as compared with the number in the control group.

The ultrastructure of the HTF cells was further evaluated using a transmission electron microscope. As indicated in Fig. 5A and B, the normal HTF cells demonstrated a spindle shape. The oval-shaped nucleus was large, and represented $1 / 3$ of the cell, which also contained one, two or multiple nucleoli. Furthermore, the cells had a clearly dilated cystic shape with rough endoplasmic reticulum that contained isopycnic fine particles or an isotropic substance. The intracellular space was filled with free Palade granules and ribosomes. By contrast, morphological changes typical of apoptosis could be observed in the HTF-TK-CD cell group treated with GCV and 5-FC for $72 \mathrm{~h}$. The characteristics of apoptosis included cell pyknosis, chromatin condensation, disappearance of organelles, cytomorphosis and typical apoptotic bodies. However, the cell membrane retained its integrity (Fig. 5C and D).

\section{Discussion}

Suicide gene therapy is a gene-directed enzyme prodrug therapy that is based on the introduction of a viral or bacterial gene that encodes a metabolic enzyme into target cells, which allows the conversion of a non-toxic compound into a lethal drug, causing the death of target cells (14). The 'bystander effect' is a phenomenon whereby the transduction of a small fraction of target cells with the suicide gene may result in widespread target cell death, including the non-transduced cells $(14,15)$. The most frequently used suicide gene therapy for clinical trials approved by the Food and Drug Administration is the (HSV-TK)/GCV system along with the $\mathrm{CD} / 5-\mathrm{FC}$ system (8). GCV is an antiviral drug, which may be transformed into its phosphorylated form by the enzyme when introduced into cells. The cells that express TK make it susceptible to GCV drug-induced cytotoxicity (16). However, the drug has no or low toxicity for normal mammalian cells. 5-FC is an antifungal drug compound that is non-cytotoxic but may be transformed into 5-FU following deamination by the CD gene, which may act to inhibit cellular proliferation (14).

It has been reported that suicide gene therapy may inhibit HTF proliferation when delivered using a viral vector, more evidently for single suicide gene transfection (17). The disadvantages of the viral vector system represent potential immunogenicity, carcinogenicity, inability to load long fragments and the generation of virion particles during viral recombination $(18,19)$. Additionally, there are several advantages when using PAMAM-D-mediated gene delivery compared with using a viral vector. Firstly, it is avirulent to an organism, lacks immunogenicity and is able to load long fragments of DNA $(20,21)$. Secondly, it protects the target gene from destruction by complement system in plasma or histocytes $(20,21)$. Lastly, it may mediate exogenous gene 


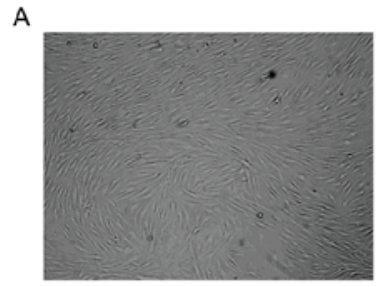

B

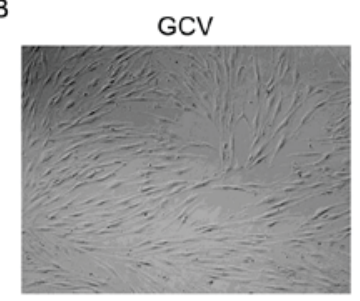

$5-\mathrm{FC}$

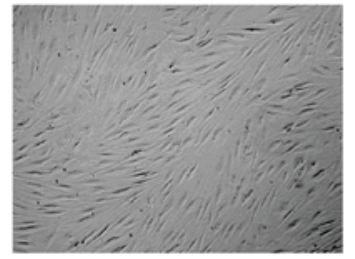

GCV/5-FC

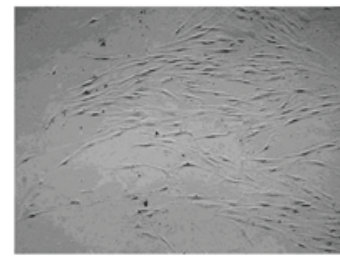

C

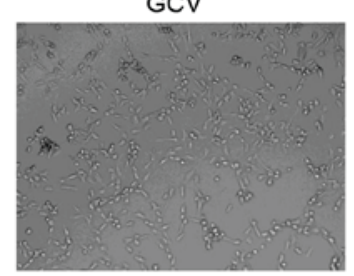

$5-\mathrm{FC}$

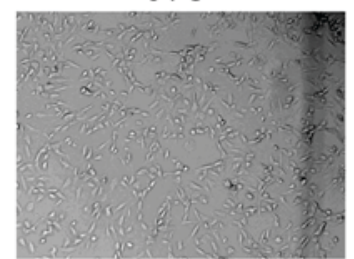

GCV/5-FC

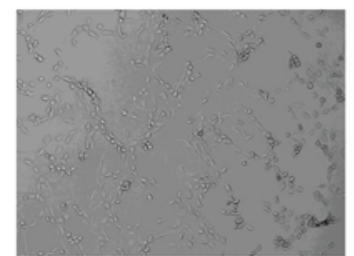

Figure 4. Effect of 5-FC and GCV on HTF cell morphology was accessed by light microscopy. (A) Normal HTF cells demonstrated typical array polarity (magnification, x100). (B) HTF cells treated with GCV, 5-FC or GCV/5-FC (magnification, x100) (C) HTF-TK-CD cells treated with GCV, 5-FC or GCV/5-FC (magnification, x100). 5-FC, 5-flurocytosine; GCV, ganciclovir HTFs, human Tenon's capsule fibroblasts; TK, thymidine kinase; CD, cytosine deaminase.

A

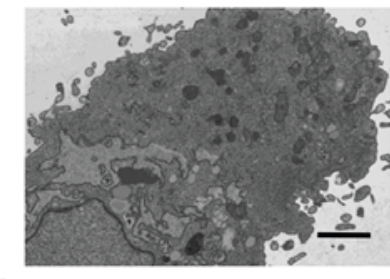

C

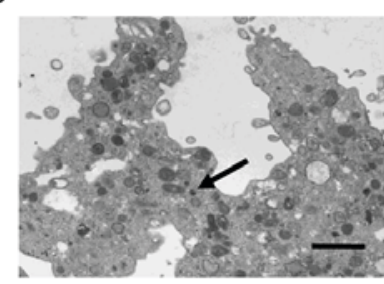

B

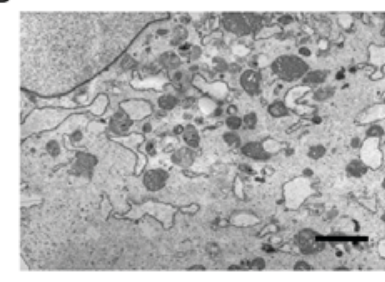

D

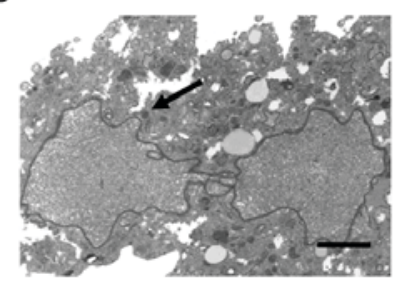

Figure 5. Effect of 5-FC and GCV on HTF cells was accessed by transmission electron microscopy. (A and B) Ultrastructure of normal HTFs. (C and D) Larger regular chromatin ball typical for apoptosis was observed in HTFs-TK-CD treated with the prodrug for $72 \mathrm{~h}$ (apoptotic body, black arrows). Scale bar, $2 \mu \mathrm{m}$. Cells were double-stained with $3 \%$ uranyl acetate and lead citrate. Magnification: A, x3,400; B, x5,700; C, x3,400; D, x3,400. 5-FC, 5-flurocytosine; GCV, ganciclovir; HTFs, human Tenon's capsule fibroblasts; TK, thymidine kinase; $\mathrm{CD}$, cytosine deaminase.

integration in host cell chromosomal DNA, which may result in long-lasting and stable expression of a transgene $(12,21)$.

Double suicide gene therapy represents the genetic integration of two types of suicide genes that express a fusion gene product with a double gene encoding enzyme activity in the target cell (21). In the present study, the plasmid of the double suicide gene, pAcGFP1-Hyg-TK-CD, was used to transfect HTF cells with a G5-PAMAM-D vector. The results of the MTT assay indicated that the cell survival ratio was significantly reduced when an increased concentration of the prodrug was added to the TK-CD-transfected HTF cells. Furthermore, the cell survival rate in the drug combination group was evidently lower than that in the single drug group. When $3 \mu \mathrm{g} / \mathrm{ml} \mathrm{GCV}+200 \mu \mathrm{g} / \mathrm{ml} 5$-FC was administered, the cell survival rate was $24.35 \%$, which was lower than that of the single administration of $3 \mu \mathrm{g} / \mathrm{ml}$ of GCV or $200 \mu \mathrm{g} / \mathrm{ml}$ of $5-\mathrm{FC}$ (40.18 and $38.46 \%$, respectively). Furthermore, inhibition of transfected cells with the drug combination was greater than that of cells treated with a single drug. This result indicated that the TK-CD gene combination could exhibit a synergetic effect due to differentially-expressed enzymes that possess different sites of action, and the present data are consistent with the result from a previous study (22). There are several possible reasons that may account for this synergetic effect $(7,9)$. Firstly, TK but not CD is a cell cycle-specific agent and the TK-CD combination could kill cells in dividing and quiescent stages. Secondly, TK/GCV exerts its 'bystander effect' on cellular gap junctions, while 5-FC acts on cell membranes, and CD/5-FC was independent of cellular gap junctions, allowing the combination to kill target cells with and without gap junctions (7). Lastly, the activity of GCV phosphorylation with HSV/TK was significantly increased in the presence of 5-FC.

In the present study, by observing HTF cells transfected with TK-CD and exposed to the prodrug GCV and 5-FC, deterioration of cell growth and shrinkage were observed, as well as a reduction in the number of cells. For the GCV and 5-FC combination compared with prodrug alone, cell growth was diminished and there were fewer cells left following prodrug treatment. HTF-TK-CD cell nuclear chromatin margination, cytoplasmic condensation and cell deformation were observed by transmission electron microscopy. Additionally, typical apoptotic bodies were visible while the cell membrane was intact, indicating that the cells were in an ongoing apoptotic process. Altogether, these observations indicated that the TK-CD double suicide gene system could initiate apoptosis in HTF cells.

While G5-PAMAM-D-mediated gene transfection efficiency requires further improvement, the notable characteristic of the suicide gene/prodrug system is the existence of a 'bystander effect', whereby the transduction of a small fraction of target cells with the suicide gene may result in widespread target cell death, including non-transduced cells, causing exacerbation of the lethal effect. A preliminary study of the mechanism of the 'bystander effect' was reported previously (23). Different suicide genes may act by different mechanisms, for example the TK gene, but not the CD gene, was localized to gap junctions (7). Furthermore, the system may be effective without reaching high transfection efficiency. The 'bystander effect' of double suicide genes is more powerful than that of a single suicide gene (24). Nevertheless, 
further theoretical and experimental studies are warranted to demonstrate that double suicide genes act by synergism or accumulation (24).

In summary, the present study demonstrated that the G5-PAMAM-D nanoparticle-mediated double suicide gene TK and CD system inhibited HTF cell proliferation in vitro, and exerted a 'bystander effect'. The present study may provide a novel framework for gene therapy to treat filtering bleb scarring following glaucoma filtering surgery. HTF-specific delivery by G5-PAMAM-D-mediated double suicide TK-CD gene with the addition of specific fibroblast enhancers or promoters upstream of the suicide gene may be used as an antiscarring agent and provide a therapeutic potential for patients receiving glaucoma filtration surgery.

\section{Acknowledgements}

The present study was supported by Tianjin Municipal Science and Technology Commission (grant no. 13JCYBJC21500).

\section{References}

1. Law SK, Shih K, Tran DH, Coleman AL and Caprioli J: Long-term outcomes of repeat vs initial trabeculectomy in open-angle glaucoma. Am J Ophthalmol 148: 685-695.e1, 2009.

2. Steplewski A and Fertala A: Inhibition of collagen fibril formation. Fibrogenesis Tissue Repair 5 (Suppl 1): S29, 2012.

3. Gedde SJ, Heuer DK and Parrish RK II; Tube Versus Trabeculectomy Study Group: Review of results from the tube versus trabeculectomy study. Curr Opin Ophthalmol 21: 123-128, 2010.

4. Seet LF, Su R, Barathi VA, Lee WS, Poh R, Heng YM, Manser E, Vithana EN, Aung T, Weaver M, et al: SPARC deficiency results in improved surgical survival in a novel mouse model of glaucoma filtration surgery. PLoS One 5: e9415, 2010.

5. Lama PJ and Fechtner RD: Antifibrotics and wound healing in glaucoma surgery. Surv Ophthalmol 48: 314-346, 2003.

6. Moolten FL: Tumor chemosensitivity conferred by inserted herpes thymidine kinase genes: Paradigm for a prospective cancer control strategy. Cancer Res 46: 5276-5281, 1986.

7. Lee YJ, Galoforo SS, Battle P, Lee H, Corry PM and Jessup JM: Replicating adenoviral vector-mediated transfer of a heat-inducible double suicide gene for gene therapy. Cancer Gene Ther 8 : 397-404, 2001

8. Karjoo Z, Chen X and Hatefi A: Progress and problems with the use of suicide genes for targeted cancer therapy. Adv Drug Deliv Rev 99: 113-128, 2016.
9. Moriuchi S, Wolfe D, Tamura M, Yoshimine T, Miura F, Cohen JB and Glorioso JC: Double suicide gene therapy using a replication defective herpes simplex virus vector reveals reciprocal interference in a malignant glioma model. Gene Ther 9: 584-591, 2002.

10. Martín F, Chowdhury S, Neil S, Phillipps N and Collins MK: Envelope-targeted retrovirus vectors transduce melanoma xenografts but not spleen or liver. Mol Ther 5: 269-274, 2002.

11. Vargas J Jr, Klotman ME and Cara A: Conditionally replicating lentiviral-hybrid episomal vectors for suicide gene therapy. Antiviral Res 80: 288-294, 2008.

12. Eichman JD, Bielinska AU, Kukowska-Latallo JF and Baker JR Jr: The use of PAMAM dendrimers in the efficient transfer of genetic material into cells. Pharm Sci Technolo Today 3: 232-245, 2000.

13. Andonova VY: A new direction in ophthalmic development: Nanoparticle drug delivery systems. Curr Pharm Des 22: 6313-6329, 2016.

14. Chaszczewska-Markowska M, Stebelska K, Sikorski A, Madej J, Opolski A and Ugorski M: Liposomal formulation of 5-fluorocytosine in suicide gene therapy with cytosine deaminase-for colorectal cancer. Cancer Lett 262: 164-172, 2008.

15. Duarte S, Carle G,Faneca H, de Lima MC and Pierrefite-Carle V: Suicide gene therapy in cancer: Where do we stand now? Cancer Lett 324: 160-170, 2012

16. Candice LW, Django S and Margaret EB: The role of herpes simplex virus- 1 thymidine kinase alanine 168 in substrate specificity. Open Biochem J 2: 60-66, 2008.

17. Wang JB, Ge J, Liu BQ, Huang B and Wei YT: Anti-proliferative effect of herpes simplex virus thymidine kinase gene system on human Tenon capsule fibroblasts in vitro. Zhonghua Yan $\mathrm{Ke} \mathrm{Za}$ Zhi 42: 212-217, 2006.

18. Larocca C and Schlom J: Viral vector-based therapeutic cancer vaccines. Cancer J 17: 359-371. 2011

19. Kajiwara E, Kawano K, Hattori Y, Fukushima M, Hayashi K and Maitani Y: Long-circulating liposome-encapsulated ganciclovir enhances the efficacy of HSV-TK suicide gene therapy. J Control Release 120: 104-110. 2007.

20. Taghavi Pourianazar N and Gunduz U: CpG oligodeoxynucleotide-loaded PAMAM dendrimer-coated magnetic nanoparticles promote apoptosis in breast cancer cells. Biomed Pharmacother 78: 81-91. 2016.

21. Chen Y, Wang G, Kong D, Zhang Z, Yang K, Liu R, Zhao W and $\mathrm{Xu} Y$ : In vitro and in vivo double-enhanced suicide gene therapy mediated by generation 5 polyamidoamine dendrimers for PC-3 cell line. World J Surg Oncol 10: 3, 2012.

22. Choi JS, Nam K, Park JY, Kim JB, Lee JK and Park JS: Enhanced transfection efficiency of PAMAM dendrimer by surface modification with L-arginine. J Control Release 99: 445-456, 2004.

23. Denny WA: Prodrugs for gene-directed enzyme-prodrug therapy (Suicide Gene Therapy). J Biomed Biotechnol 2003: 48-70, 2003.

24. Jia W, Mei L, Wang Y, Liu L and Che G: Double suicide genes selectively kill human umbilical vein endothelial cells. Virol J 8: $74,2011$. 